\title{
Structural Relationships among Household Chaos, Maternal Negative Parenting, Child Executive Function, and Child Aggression
}

\author{
Jeong Min Lee ${ }^{1}$, Sunhee Kim ${ }^{2}$ \\ M. A., Department of Child Development and Family Studies, Pusan National University, Busan, Korea ${ }^{1}$ \\ Professor, Department of Child Development and Family Studies, Pusan National University, Busan, Korea ${ }^{2}$ \\ 가정환경 혼돈, 어머니의 부정적 양육행동, 유아의 실행기능과 \\ 공격성 간의 구조적 관계 \\ 이정민 ${ }^{1}$, 김선희 ${ }^{2}$ \\ 부산대학교 아동가족학과 석사 ${ }^{1}$, 부산대학교 아동가족학과 교수 ${ }^{2}$
}

\begin{abstract}
Objectives: This study aimed to identify the structural relationships among household chaos, maternal negative parenting behavior, child execution function, and child aggression; further, it demonstrates the mediating effects of maternal negative parenting and child execution function on the relationship between household chaos and child aggression.

Methods: The participants comprised 206 children, aged between 3 and 5, and their mothers. This study observed Cronbach' $\alpha$ and the descriptive statistics and performed frequency analysis, one-way random analysis, and partial correlation analysis via SPSS 20.0 program. The bootstrapping method was used to examine the mediating effect while the structural equation model analysis was performed using AMOS 22.0.

Results: First, child aggression was positively associated with household chaos, mother's intrusiveness, coercion, and neglect parenting but negatively associated with child inhibition, transition, working memory, and satisfaction delay tasks. Second, maternal negative parenting and child executive function were shown to mediate sequentially in the relationship between household chaos and child aggression. It was also found that maternal negative parenting and child executive function were partially mediated in the relationship between household chaos and child aggression.

Conclusion: The data suggest the importance of mediating the effects of maternal negative parenting and child executive function on the relationship between household chaos and child aggression. These findings could highlight the significance of child executive function for the development of aggression and provide the basic data for the program to help those children who show aggressive behaviors in their early childhood educational institutions along with the evidence of parental education programs.
\end{abstract}

Keywords: household chaos, maternal negative parenting, executive function, aggression

\section{Introduction}

공격성이란 타인에게 의도적으로 신체적, 심리적 해를 입히

Corresponding Author: Sunhee Kim, Professor, Department of Child Development and Family Studies, Pusan National University, 2, Busandaehak-ro 63beon-gil, Geumjeong-gu, Busan, Korea

E-mail: kremedy@pusan.ac.kr
려 하는 행동이다(Jo \& Chung, 2020). 유아는 자기중심적인 사고와 감정조절의 어려움으로 인해 욕구가 좌절되거나 갈등 상황에서 공격적 행동을 빈번히 드러낸다(Marrion, 1994). 또

(C) The Korean Association of Child Studies

This is an Open Access article distributed under the terms of the Creative Commons Attribution Non-Commercial License (http:// creativecommons.org/licenses/by-nc/4.0) which permits unrestricted noncommercial use, distribution, and reproduction in any medium, provided the original work is properly cited. 
한 유아기는 영아기와 달리 의도를 가지고 상대방을 때리거나 고함을 지르는 공격적 행동이 나타나는 시기이다(C. Y. Choi, 2019). 이 시기에 높은 수준의 공격성을 보이는 유아는 사회적 기술의 부족으로 인해 또래 집단으로부터 배척되며 유아교육 기관 적응에도 어려움을 갖는다(Kim, H. J, \& Kim, Y. H. 2011; Jeong \& Lee, 2014). 더구나 공격성은 지속적이고 안정적인 특 성이 있어서 유아기의 높은 공격성은 이후 청소년기 비행과 품행장애 등의 부적응 행동으로 이어질 수 있다(Broidy et al., 2003). 그러므로 공격성에 대한 조기 개입 방안으로서, 유아기 공격성에 영향을 미치는 요인들을 확인하고 그 관련성을 규명 하는 것은 무엇보다 중요하다.

이러한 필요성에 의해 유아의 공격성에 영향을 미치는 다 양한 요인들에 대한 연구들이 진행되어왔다. 유아기 공격성에 대한 선행연구를 살펴보면 유아 개인적 요인으로 기질(Moon $\&$ Hong, 2013), 자기조절(Youn, Kang, \& Lee, 2005), 실행기능 (Y. S. Kong, 2012) 등이 있고, 환경적 요인으로는 가정환경 혼 돈(Coldwell, Pike, \& Dunn, 2006), 어머니의 양육행동(Kim \& Shin, 2020), 어머니 양육스트레스(Oh \& Yeon, 2018) 등이 있다.

유아의 공격성에 영향을 미치는 환경적 요인 중 가정환경은 유아가 출생 후 접하는 일차적 환경으로 가장 직접적이고 중대 한 영향을 미친다. 일반적으로 가정환경은 유아의 발달을 촉 진하는 물리적, 심리적 자극을 제공하는데, 이러한 자극이 얼 마나 일관성 있고 적절하게 제공되는가에 따라 유아의 발달 양 상은 달라진다. 최근 몇몇 연구자들(Hardaway, Wilson, Shaw, \& Dishion, 2012; Volckaert, \& Noel, 2018)은 가정환경 혼돈이 유 아의 공격성에 미치는 영향에 주목하고 있다. 가정환경 혼돈 (household chaos)은 구조화되지 않은 환경에서 과도한 자극이 유발되는 상태로 시간적, 공간적 무질서함으로 인해 예측이 불 가능한 상태를 의미한다(Coldwell, Pike, \& Dunn, 2006; Kang \& Park, 2020; Vernon-Feagans, Willoughby, Garrett-Peters, \& The Family Life Project Key Investigators, 2016). 즉 필요 이상의 과잉 자극이 존재하는 상태로 높은 수준의 청각적 소음, 구조화되지 않은 상태, 지나치게 빠른 생활 속도, 정돈되지 않은 공간 등을 특징으로 한다. 선행연구에 따르면 유아의 발달 영역 중 공격 성이 가정환경 혼돈과 가장 높은 관련성을 나타내었으며, 내재 화 문제행동 보다 외현화 문제행동에 더 많은 영향을 미친 것으 로 확인되었다(Dumas et al., 2005). 또한 가정환경 혼돈은 루틴 (routine)의 결핍과도 관련 있다. 루틴이란 일과의 순서가 정해 진 상태로 매일 반복되는 규칙적인 행동으로 정의된다(Sytsma et al., 2001). 일상생활 속 루틴은 유아에게 심리적 안정감을 제 공함으로써 충동성 수준을 낮추고(Pruitt, 1998), 반복되는 규칙
적인 행동은 유아가 일상 규칙을 습득하거나 사회적 규칙을 내 면화하도록 하여 공격성 수준을 낮춘다(Sytsma et al., 2001). 반 면 과도한 자극이 존재하고 무질서한 가정환경은 유아의 공격 성을 유발할 수 있다. 가정환경 혼돈에 지속적으로 노출된 유아 는 과도한 자극으로 인해 집중력이 저하되어 오히려 사회적 단 서에 민감하게 반응하지 못하고, 부정적인 정서가 쉽게 유발되 어 높은 수준의 공격성을 보였다(Dumas et al., 2005).

가정환경 혼돈은 유아의 공격성에 직접적인 영향을 미치 기도 하지만, 어머니의 양육행동을 통해 간접적인 영향을 미 친다(Mills-Koonce, 2016). 가정환경이 무질서하고 예측이 불 가능할수록 어머니는 정신적, 육체적 피로를 경험하면서 자 녀 양육에 어려움을 겪고, 자녀와의 지속적인 상호작용에 참 여할 기회가 감소 된다. 가정환경의 혼돈 수준이 높은 가정의 어머니는 긴장과 스트레스로 인해 자녀의 요구에 민감하게 반 응하지 않고 양육에 적극적으로 참여하려는 동기가 낮아 자녀 를 온정적으로 대하지 않는 등 부정적인 양육행동을 나타냈다 (Dumas et al., 2005; Vernon-Feagans et al, 2012; Vernon-Feagans et al, 2016). 어머니의 부정적인 양육행동은 자녀의 행동을 간 섭하거나 지시하는 개입적 양육행동, 자녀에게 신체적으로 처벌을 하거나 화를 내는 강압적 양육행동과 자녀를 돌보지 않고 무관심으로 대하는 방임적 양육행동을 의미한다(J. Na, 2012). 이러한 어머니의 부정적 양육행동은 유아의 공격성을 증가시킨다(Choi \& Moon, 2016). 어머니로부터 적절한 애정 과 관심을 받지 못한 유아는 좌절감을 경험하고, 이러한 좌절 감은 대인관계에서 적대적이고 공격적인 행동으로 나타났다 (Kim \& Doh, 2001). 또한 어머니가 자녀의 감정을 자유롭게 표현하지 못하도록 하는 경우 유아는 자신의 억압된 감정을 공격적인 행동으로 표출하였다(Choi \& Moon, 2016). 따라서 가정환경 혼돈은 어머니의 부정적 양육행동을 매개하여 유아 의 공격성에 간접적인 영향을 줄 것이라 예상할 수 있다.

한편 유아의 공격성은 자신의 행동을 스스로 통제하고 결 정할 수 있는 개인 내적 능력에 따라 달라진다. 최근 연구자 들(Kim \& Shin, 2020; O’Toole, Monks, \& Tsermentseli, 2017) 은 유아의 공격성을 감소시킬 수 있는 유아의 실행기능에 주 목하고 있다. 실행기능이란 자신의 생각과 행동을 의식적 으로 관리.통제하고 목표를 성취하기 위해 적절한 문제 해 결 전략을 계획하고 유지하는 고차원적인 인지능력이다 (Welsh, Pennington, \& Grosser, 1991). 실행기능은 인지적 실행 기능(cool executive function)과 정서적 실행기능(hot executive function)으로 분류된다(Zelazo \& Muller, 2002). 인지적 실행기 능은 비맥락적이고 중립적인 상황에서 요구되는 반면, 정서 
적 실행기능은 정서 및 동기와 같은 맥락에서 발현되는 능력 이다(Zelazo \& Muller, 2002). 이러한 실행기능은 전두엽 발달 과 관련이 있으며 생후 1 년부터 청소년기까지 지속적으로 발 달하는데, 만 3세에서 만 5세까지 해당하는 유아기는 전두엽 의 급격한 발달과 함께 실행기능이 급속하게 발달한다(Garon, Bryson, \& Smith, 2008). 실행기능이 낮은 유아는 자신의 행동 을 억제하거나 갈등을 해결하는 능력이 부족하여 타인을 공격 하거나 괴롭히는 행동을 더 많이 보였으며(Y. S. Kong, 2012), 타인의 의도를 적대적으로 해석하는 경향이 있고 문제 해결을 위한 계획능력이 저하되어 공격적인 행동을 더 많이 보였다 (Ellis, Weiss, \& Lochman, 2009). 이는 자신의 사고와 행동을 통 제하고 문제 해결 전략을 계획하는 인지능력인, 실행기능 수 준이 낮은 유아는 자신의 욕구가 충족되지 않는 상황에서 타 인을 밀치고 때리는 등의 공격성을 보이기 쉬움을 의미한다.

유아의 공격성에 영향을 미치는 실행기능 또한 가정환경의 특성에 따라 달라진다. 유아가 혼란스런 가정환경에 노출될 경 우 지속적인 스트레스를 경험하는데 이는 전전두엽 피질의 구 조적, 기능적 변화를 초래함으로써 실행기능 발달을 어렵게 한 다(Volckaert \& Noel, 2018). 또한 무질서하고 과도한 자극이 있 는 가정환경에 노출된 유아는 환경을 통제하는데 실패를 자주 경험함으로써 환경을 통제할 수 없다는 무력감을 가지게 되고, 이는 자신의 사고를 조절하고 유지하는 능력인 실행기능의 발 달에도 부정적인 영향을 미쳤다(Evans \& Stecker, 2004). 환경 과부화 이론(environmental load theory)에 따르면, 사람은 자극 을 처리하는 능력에 한계가 있어 많은 주의를 기울여야 하거나 예측 불가능한 자극이 많아질수록 정보를 효율적으로 처리하 기 어렵다(Millgram, 1970). 특히 어린 유아는 관련 없는 자극을 변별하는 능력이 부족하고(Evans \& Wachs, 2010), 과도한 자극 을 걸러내기 위한 전략을 생성하고 선택하여 사용하는 데 어려 움이 있어(Wachs \& Evans, 2010), 가정환경 혼돈으로 인한 부정 적인 영향이 더 크게 작용할 가능성이 높다.

또한 가정환경 혼돈과 더불어 어머니의 부정적 양육행동 은 유아의 실행기능 발달을 저해한다. 어머니의 지나친 통제 와 개입은 유아가 스스로 탐색할 수 있는 기회를 제한하여 실 행기능 발달을 지연시킨다(Graziano, 2009). 또한 어머니가 무 관심하거나 방임적인 양육행동을 하는 경우 유아는 실행기 능 과제에서 주의가 산만하여 낮은 수행능력을 보였다(Bernie, Carlson, \& Whippler, 2010). 따라서 개입적이고 강압적이거나 방임적인 어머니의 양육행동은 유아의 실행기능에 부정적인 영향을 미침을 알 수 있다. 그리고 앞서 서술한 바와 같이 가정 환경 혼돈은 어머니로 하여금 부정적 양육행동을 할 가능성을
높인다. 가정환경 혼돈 수준이 높을수록 어머니는 자녀의 행 동을 지나치게 간섭하고, 강압적이거나 자녀를 돌보지 않는 경향이 있다(Dumas et al., 2005; Vernon-Feagans et al., 2016). 따 라서 가정환경 혼돈은 유아의 실행기능에 직접적인 영향을 주 는 동시에 어머니의 부정적 양육행동을 매개하여 유아의 실행 기능에 영향을 미칠 것으로 예상할 수 있다.

종합해보면 가정환경 혼돈이 어머니의 부정적 양육행동과 유아의 실행기능을 매개하여 유아의 공격성에 영향을 미치는 것 을 예상할 수 있다. 즉 자극과 무질서 수준이 높고, 자녀로 하여 금 일상 활동을 예측하기 어렵게 하는 가정환경 혼돈은 유아의 공격성 발달에 직접적인 영향을 미칠 뿐만 아니라 가정환경 혼 돈은 어머니의 부정적인 양육행동을 유발하고 이는 다시 유아 의 실행기능 발달을 저해함으로써 유아의 공격성에 간접적인 영 향을 미칠 것으로 예상된다. 선행 연구들은 가정환경 혼돈, 어머 니의 부정적 양육행동, 유아의 실행기능 각각이 공격성에 미치 는 개별적인 영향을 확인하거나, 이들 변인 중 일부 변인들 간의 매개관계를 부분적으로 검증하였다. 따라서 본 연구에서는 가 정환경 혼돈이 유아의 공격성에 이르는 과정에 관여하는 어머니 의 부정적 양육행동과 유아의 실행기능의 매개적 역할을 통합 적으로 확인함으로써 가정환경 혼돈으로 인한 유아의 공격성을 예방하고 감소시키기 위한 방안을 제시하고자 한다.

본 연구는 선행연구에 근거하여 다음과 같이 연구문제와 가설적 연구모형을 설정하였다(Figure 1).

\section{연구문제 1}

가정환경 혼돈, 어머니의 부정적 양육행동, 유아의 실행기능 그리고 공격성 간의 관계는 어떠한가?

\section{연구문제 2}

가정환경 혼돈과 유아의 공격성 간의 관계에서 어머니의 부 정적 양육행동과 유아의 실행기능이 매개하는가?

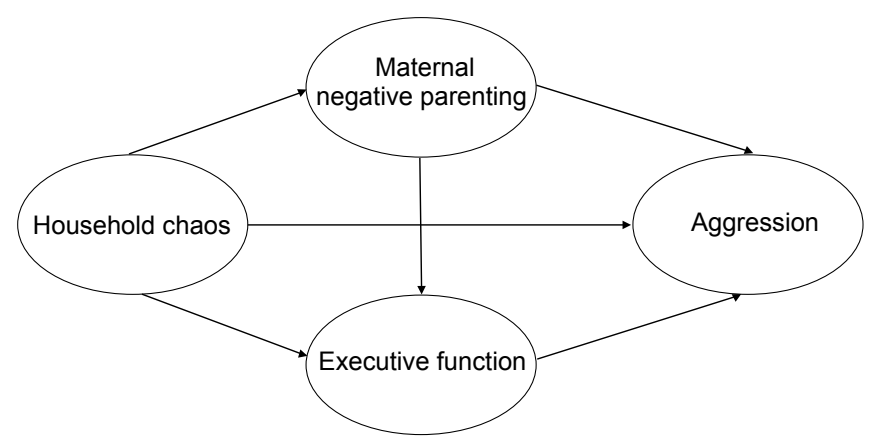

Figure 1. Hypothesized Study Model. 


\section{Methods}

\section{연구대상}

본 연구의 대상은 어린이집에 재원하고 있는 만 $3,4,5$ 세 남녀 유아 총 206명(남아 120 명, 여아 86명)과 그들의 어머니이다. 연구대상자의 일반적 특성을 살펴보면, 유아의 연령은 만 3세 60명(29.1\%), 만 4세 63명(30.6\%), 만 5세 83명(40.3\%)이었고, 성별은 남아 120 명(58.3\%), 여아 86명(41.7\%)이었다. 어머니 의 연령은 36-40세가 100 명(48.5\%)으로 가장 많았고, 어머니 의 학력은 대학교 졸업이 100 명(48.5\%)으로 가장 많았다. 어 머니의 직업은 무직, 학생, 가정주부가 83명(40.3\%)으로 가장 많았고, 그 뒤로 일반회사, 공공기관, 공무원이 41 명(19.9\%)등 이 있었다. 가정의 월평균소득은 501만원 이상이 92명(44.7\%) 으로 가장 많았다.

\section{연구도구}

\section{유아의 공격성}

유아의 공격성을 측정하기 위해 Achenbach와 Rescorla(2000) 가 개발한 유아 행동평가척도(Korean Child Behavior Checklist [CBCL]) 1.5-5를 Y. A. Kim 등 (2009)이 표준화한 한국판 유아 행동평가척도(Korean Child Behavior Checklist [K-CBCL])1.5-5 척도 중 공격성에 해당하는 19 문항을 사용하였다. 각 문항은 유아의 어머니가 평정하였으며 3점 척도로 구성되어 있다. 점 수가 높을수록 유아의 공격성이 높은 것을 의미한다. 문항을 살펴보면 "가족이나 다른 아이의 물건을 부순다.", “싸움을 많 이 한다.”, “화가 나 보인다.” 등이 있다. 본 도구의 Cronbach's $\alpha$ 계수는 .87로 나타났다.

\section{가정환경 혼돈}

가정환경 혼돈을 측정하기 위해 Matheny, Wachs, Ludwig 그 리고 Phillips (1995)가 개발한 가정환경 혼돈 척도(Confusion, Hubbub, and Order Scale [CHAOS])를 D. Y. Kang과 J. H. Park (2020)가 번안한 척도를 사용하였다. 이 척도는 총 15 문항으로 구성되어 있으며 이 중 질서를 나타내는 7 개의 문항은 역채점 하였다. 각 문항은 유아의 어머니가 측정하였으며 4점 척도로 구성되어 있다. 총점이 높을수록 가정환경 혼돈 수준이 높음 을 의미한다. 문항을 살펴보면 “우리는 항상 서두르는 것처럼
보인다”, “우리가 무엇을 계획하든지 간에 거의 그대로 진행 되지 않는다.", "우리는 아침에 일어나서 함께하는 규칙적인 일과가 있다." 등이 있다. 본 도구의 Cronbach's $\alpha$ 계수는 .80으 로 나타났다.

\section{어머니의 부정적 양육행동}

어머니의 부정적 양육행동을 측정하기 위해 S. H. Lee (2012) 가 개발한 학령기 자녀를 둔 부모의 양육행동 척도를 J. H. Na (2012)가 유아기 자녀를 둔 부모용으로 수정한 척도를 사용하 였다. 본 척도에서 부정적 양육행동에 해당하는 개입적 양육 행동(9문항), 강압적 양육행동(7문항), 방임적 양육행동(10문 항)을 사용하였다. 각 문항은 유아의 어머니가 측정하였으며 4점 척도로 구성되어 있다. 총점이 높을수록 어머니가 개입적 이고 강압적이며 방임적인 양육행동을 많이 보임을 의미한다. 개입적 양육행동의 문항을 살펴보면 "아이의 행동에 대해 지 적을 많이 한다.", "아이의 실수에 대해 비난을 한다.” 등이 있 으며, 강압적 양육행동의 문항에는 "이유를 설명하기 보다는 벌로써 아이를 지도한다.”, 아이가 잘못된 행동을 할 때 고함 을 지른다. “등이 있다. 방임적 양육행동의 문항내용은 "아이 에 대해 관심이 없어서 칭찬하거나 혼내는 일이 없다.", "아이 가 어떤 생각을 하고 있는지에 대해 관심이 없다." 등이 있다. 본 도구의 Cronbach's $\alpha$ 계수는 전체 .88, 개입 .86 , 강압 .84 , 방 임 81 로 나타났다.

\section{유아의 실행기능}

유아의 실행기능을 측정하기 위해 인지적 실행기능 영역인 인지적 억제, 인지적 전환, 그리고 작업기억과 정의적 실행기 능 영역인 만족지연 과제를 실시하였다.

억제 유아의 인지적 억제 능력을 측정하기 위해 Gerstadt, Hong과 Diamond (1994)가 개발한 낮-밤 과제(Day-Night)를 사 용하였다. 이 과업은 유아가 우세한 인지적 반응을 얼마나 억 제할 수 있는지 측정하는 검사이다. 유아는 해 그림카드를 보 면 밤이라고 해야 하고, 달 그림카드를 보면 낮이라고 말해야 한다. 과제는 4 번의 연습시행과 16 번의 본 시행으로 이루어진 다. 유아가 이해했다고 판단되면 16장의 카드를 순서대로 제 시한다. 16 번의 시행에서 유아가 지시대로 맞게 대답한 횟수 를 기록 하여 채점하며, 총점의 범위는 0-16점이다. 점수가 높 을수록 유아의 인지적 억제 능력이 높음을 의미한다. 
전환 유아의 인지적 전환능력을 측정하기 위해 Frye, Zelazo 와 Palfai (1995)의 카드분류과제(Dimensionnal Change Card Sort Task [DCCS])를 사용하였다. 검사는 총 세 가지 규칙으로 진행되었다. 첫 번째 규칙은 색 범주로 카드를 분류하게 하고, 두 번째 규칙은 모양 범주로, 세 번째 규칙은 앞의 두 가지 방 법에 테두리 범주를 추가하여 테두리가 있으면 색으로 분류 하고, 테두리가 없으면 모양 범주에 따라 카드를 분류하게 하 였다. 과제를 시행하기 전에 반복하여 설명하는 시간을 가진 후 유아가 내용을 이해하는지를 확인한 이후 검사를 실시하였 다. 색과 모양 규칙은 각 6회 연속으로 시행하고 테두리 규칙 은 12 회 연속으로 시행하였다. 유아가 규칙에 맞게 분류하면 1 점, 실패하면 0 점을 부여하였다. 색과 모양 규칙에 따른 점수 범위는 각 0 점에서 6점으로, 합산하면 0 점에서 12 점의 범위를 갖는다. 테두리 규칙에 따른 점수는 0 점에서 12 점의 범위를 가지며, 색과 모양, 테두리 규칙에 따른 점수를 모두 합산하면 총점의 범위는 0 에서 24점으로 점수가 높을수록 유아의 인지 적 전환 능력이 뛰어남을 의미한다.

작업기억 유아의 작업기억을 측정하기 위해 Diamond와 Taylor (1996)의 과제를 Hughes (1998)가 변형하고, 국내에서 J. $\operatorname{Kim}$ (2013)이 사용한 8개 상자과제를 사용하였다. 색깔 종이 컵을 4개씩 2줄로 배열한 후, 유아가 보는 앞에서 지우개를 한 개씩 각 종이컵에 넣은 후 유아에게 색깔 종이컵에 든 지우개 를 모두 찾는 게임이라고 소개한다. 유아가 원하는 색의 종이 컵을 하나 뒤집어 지우개를 꺼내도록 한다. 유아가 지우개를 꺼내면 검사자는 그 자리에 종이컵을 덮은 후 다시 뒤집어 종 이컵 안에 지우개가 없음을 확인시켜준다. 본 검사는 유아가 이미 지우개를 꺼낸 하나의 종이컵을 제외한 7 개 지우개가 종 이컵에 들어 있는 상태에서 시작한다. 유아가 종이컵을 선택 한 직후 지우개의 유무에 관계없이 매번 눈을 감고 검사자가 1 에서 10 까지 세면서 종이컵의 위치를 바꾸어 놓는다.

검사는 가장 적은 시행으로 7 개의 지우개를 모두 찾는 것으 로 작업기억을 측정하며, 유아는 15 회의 기회를 부여받는다. 유아가 지우개를 모두 찾아내거나 지우개를 찾지 못하고 종이 컵을 뒤집어 보는 횟수가 15 회가 될 때까지만 검사를 진행한 다. 유아가 실수 없이 7개의 지우개를 연속으로 7회 시도하여 찾은 경우 0 점을, 두 번 실수를 하여 9 번 만에 7 개의 지우개를 찾으면 2점을 부여한다. 이미 지우개를 찾은 종이컵을 뒤집어 15 회로 검사를 마친 경우 8점이 부여된다. 총 점수의 범위는 0-8점으로 점수가 높을수록 유아의 작업기억이 낮음을 의미 하므로 역코딩을 실시하였다.
만족지연 유아의 만족지연 능력을 측정하기 위해 Prencipe 과 Zelazo (2005)가 고안한 만족지연과제 사용하였다. 이 과제 는 유아가 미래의 더 큰 만족을 위해 지금 당장의 만족을 미루 는 능력을 측정한다. 만족지연과제에는 싸인펜, 비타민, 젤리 세 가지 보상물이 사용되는데, 연구자는 유아에게 이 세 가지 보상물을 지금 가질 것인지, 나중(점심시간 이후 또는 집에 갈 때)에 더 많은 보상물을 가질 것인지를 선택하게 한다. 유아가 지금을 선택하는 경우 보상물은 즉시 제공되지만, 나중을 선 택하는 경우 보상물은 탁자 가장자리에 놓여진 봉투에 담아 점심시간 이후 또는 귀가 시 담임교사를 통해 전달한다. 지금 을 선택한 경우 유아가 원할 시 젤리, 비타민을 바로 먹거나 싸 인펜을 사용하는 것을 허용하였다. 과제를 제시할 때는 각 보 상물의 사진을 찍어 카드로 제작한 것을 사용하였다. 과제 제 시는 젤리 $1: 6$ (지금 젤리 하나와 나중 젤리 6개 중 선택), 싸인 펜 $1: 2$, 비타민 $1: 4$, 젤리 $1: 2$, 비타민 $1: 2$, 싸인펜 $1: 4$, 젤리 $1: 4$, 비타민 $1: 6$, 싸인펜 $1: 6$ 의 순서로 진행하였다. 유아에 게 9번의 선택기회가 제공되며 점수 범위는 0-9점이다. 이 중 유아가 나중을 선택한 횟수를 만족 지연 점수로 사용하였다.

\section{통제변인}

선행연구(Y. S. Kong, 2012; S. B. Shin, 2019)에 의하면 유아의 실행기능은 유아의 연령에 따라 유의한 차이가 있는 것으로 나 타나, 본 연구에서는 유아의 연령을 통제변인으로 선정하였다.

\section{연구절차}

본 연구는 2021년 2월부터 2021년 5월에 걸쳐 경남의 어린이 집 5곳에서 유아와 해당 유아의 어머니를 대상으로 실시하였 다. 연구를 실시하기 전 어린이집에 연구에 대한 설명문과 동 의서를 배부하였으며, 어머니가 참여에 동의한 유아들을 대상 으로 연구가 진행되었다. 연구자와 아동학 석사 1 인(연구보 조원)이 유아를 대상으로 실행기능 과제를 실시하였다. 과제 는 어린이집의 독립된 공간에서 연구자와 유아가 $1: 1$ 로 마주 보고 앉아 진행하였으며, 억제, 전환, 작업기억, 만족지연 과제 가 주어졌다. 이 네 가지 과제가 주어지는 순서는 역균형화 되 었으며, 소요시간은 20 분 내외였다. 어머니를 대상으로는 가 정환경 혼돈, 어머니의 부정적 양육행동, 유아의 공격성 및 연 구대상자의 일반적 특성에 관한 내용으로 설문지를 구성하여 자료를 수집하였다. 
Table 1

Descriptive Statistics

\begin{tabular}{llcccc}
\hline & Variables & $M$ & $S D$ & Skewness & Kutosis \\
\hline Household chaos & & 2.01 & .34 & .20 & .27 \\
\hline Negative parenting & Intrusiveness & 2.05 & .45 & .20 & -.11 \\
& Coercion & 1.73 & .47 & .29 & -.51 \\
& Neglect & 1.12 & .19 & 2.88 & 9.64 \\
\hline Executive function & Inhibition & 11.63 & 5.00 & -1.05 & -.02 \\
& Transition & 16.26 & 3.44 & -.28 & -.80 \\
& Working memory & 3.99 & 2.78 & -.20 & -.13 \\
& Satisfaction delay & 5.02 & 2.92 & -.31 & -1.03 \\
\hline Aggression & & .36 & .28 & .86 & .28 \\
\hline
\end{tabular}

Note. $N=206$.

\section{자료분석}

수집된 자료는 SPSS 20.0 (IBM Co., Armonk, NY)과 AMOS 22.0 (IBM Co., Armonk, NY) 프로그램을 이용하여 분석하였 다. 측정도구의 신뢰도를 확인하기 위해 Cronbach의 $\alpha$ 계수를 산출하고, 연령에 따른 유아의 실행기능의 발달차를 알아보 기 위해 일원변량분석을 실시하였다. 연구대상의 일반적인 특 성을 살펴보기 위하여 빈도분석, 기술통계를 실시하였으며 정 규분포를 알아보기 위해 왜도와 첨도를 분석하였다. 주요 변 인들 간의 관계를 살펴보기 위해 편상관 분석을 실시하고, 가 정환경 혼돈과 유아의 공격성 간의 관계에서 어머니의 부정적 양육행동과 유아의 실행기능의 매개효과를 검증하기 위해서 구조방정식 분석을 실시하였다. 또한 매개변인들의 통계적 유 의성을 살펴보기 위해 부트스트랩 방법(Bootstrap method)을 사용하였다.

\section{Results}

\section{측정변인들의 기술통계치}

측정변인들의 기술통계치를 Table 1 에 제시하였다. 측정변수 왜도의 절대값이 3 , 첨도의 절대값 10 을 초과하지 않을 때 구 조방정식 모형에서 정규분포성의 가정을 충족하는 것으로 볼 수 있다(Kline, 2015). 따라서 본 연구의 모든 측정변수는 정규 분포성 가정에 문제가 없는 것으로 확인되었다.

\section{예비분석 및 주요 변인들 간의 상관관계}

\section{예비분석}

유아의 연령에 따른 실행기능의 차이를 확인하기 위해 일원변 량분석을 실시한 결과를 Table 2에 제시하였다.

Table 2에 의하면, 실행기능의 하위영역(억제, 전환, 작업기 억, 만족지연) 모두에서 유의한 연령 차이가 나타났으므로 유 아의 연령을 통제하여 분석할 필요성을 확인하였다.

\section{주요 변인들 간의 편상관관계 분석}

유아의 연령을 통제한 편상관계수를 통해 변인들 간의 상관관 계를 살펴보았으며, 그 결과는 Table 3 과 같다.

Table 3 에 의하면, 유아의 공격성은 가정환경 혼돈 $(r=.25, p$ <.001), 개입적 양육행동 $(r=.27, p<.001)$, 강압적 양육행동 $(r$ $=.31, p<.001)$, 방임적 양육행동 $(r=.21, p<.01)$ 과 유의미한 정적 상관관계가 나타났으며, 유아의 억제 $(r=-.20, p<.01)$, 전 환 $(r=-.21, p<.01)$, 작업기억 $(r=-.15, p<.05)$, 만족지연 $(r=-.15$, $p<.05)$ 와 유의미한 부적 상관관계가 나타났다. 이는 가정환 경 혼돈 수준이 높고 강압적 양육행동, 개입적 양육행동, 방임 적 양육행동을 많이 보일수록 유아의 공격성이 높아짐을 의미 하며 억제, 전환, 작업기억, 만족지연과제 점수가 낮아질수록 유아의 공격성이 높아짐을 의미한다. 
Table 2

Differences in Executive Function According to Age Groups

\begin{tabular}{lcccc}
\hline & 3-year-olds & 4-year-olds & 5-year-olds & Scheffe \\
& $M(S D)$ & $M(S D)$ & $M(S D)$ & $19.56^{* * *}$ \\
\hline Inhibition & $8.90(.69)$ & $11.41(.62)$ & $13.76(.40)$ & $\mathrm{a}<\mathrm{b}<\mathrm{c}$ \\
Transition & $14.55(.40)$ & $15.59(.33)$ & $18.00(.31)$ & $23.41^{* * *}$ \\
Working memory & $2.52(.32)$ & $4.09(.30)$ & $4.96(.31)$ & $15.45^{* * *}$ \\
Satisfaction delay & $3.77(.37)$ & $4.81(.37)$ & $6.08(.28)$ & $\mathrm{a}, \mathrm{b}<\mathrm{c}$ \\
\hline
\end{tabular}

Note. $N=206 . \mathrm{a}=3$-year-olds; $\mathrm{b}=4$-year-olds; c $=5$-year-olds.

*** $p<.001$.

Table 3

Partial Correlations Among Household Chaos, Maternal Negative Parenting, Executive Function and Aggression

\begin{tabular}{ccccccccc}
\hline Variables & 1 & 2 & 3 & 4 & 5 & 6 & 7 & 8 \\
\hline 1 & - & & & & & & \\
2 & $.23^{* *}$ & - & & & & & \\
3 & $.32^{* *}$ & $.54^{* * *}$ & - & & & & \\
4 & $.30^{* *}$ & $.15^{* *}$ & $.30^{* * *}$ & - & & & \\
5 & $-.23^{* *}$ & $-.21^{* *}$ & $-.20^{* *}$ & $-.23^{* *}$ & - & & \\
6 & $-.23^{* *}$ & $-.28^{* * *}$ & $-.20^{* *}$ & -.13 & $.27^{* * *}$ & - &. & \\
7 & -.12 & $-.20^{* *}$ & -.13 & -.05 & $.29^{* * *}$ & $.33^{* * *}$ & - & \\
8 & $-.21^{* *}$ & -.10 & $-.17^{*}$ & $-.17^{*}$ & $.21^{* *}$ & $.23^{* *}$ & $.29^{* *}$ & - \\
9 & $.25^{* * *}$ & $.27^{* * *}$ & $.31^{* * *}$ & $.21^{* *}$ & $-.20^{* *}$ & $-.21^{* *}$ & $-.15^{*}$ & $-.15^{*}$ \\
\hline
\end{tabular}

Note. $N=206.1$ = Household chaos; 2 = Intrusiveness parenting; 3 = Coercion parenting; 4 = Neglect parenting; 5 = Inhibition;

$6=$ Transition; 7 = Working memory; $8=$ Satisfaction delay; 9 = Aggression.

${ }^{*} p<.05 .{ }^{* *} p<.01 .{ }^{* * *} p<.001$.

Table 4

Model Fit Indices for the Research Model

\begin{tabular}{cccccccc}
\hline & $\chi^{2}$ & $d f$ & $P$ & GFI & TLI & CFI & RMSEA \\
\hline Research model & 86.07 & 71 & .11 & .93 & .98 & .99 & .03 \\
\hline
\end{tabular}

유아의 공격성에 대한 가정환경 혼돈, 어머니의 부정적 양육행동, 유아의 실행기능 간의 구조적 관계

\section{측정모형 검증}

측정모형의 타당성을 검증하기 위해 확인적 요인분석을 실시 하였고 측정모형의 적합도는 아래의 Table 4와 같다. 가정환경 혼돈과 유아의 공격성은 하나의 관측변수로 구성되는 단일요 인이므로 문항꾸러미 방법을 사용하여 측정을 위한 관측변수 를 구성하였다. 또한 $\chi^{2}$ 검증은 표본의 크기에 매우 민감하여 모형이 기각되기 쉽다는 문제점이 있으므로, 본 연구에서는
표본 크기에 의한 영향력을 최소화하기 위한 대안으로 GFI, TLI, CFI, RMSEA 모형적합도 지수를 사용하였다. 확인적 요 인분석을 실시한 결과 $\chi^{2}$ 은 $86.07(d f=71, p>.05), \mathrm{GFI}=.93$, $\mathrm{TLI}=.98, \mathrm{CFI}=.99, \mathrm{RMSEA}=.03$ 으로 본 연구의 측정모형이 수용 가능한 모델임을 확인하였다.

\section{구조모형 검증}

연구모형의 적합도를 살펴보기 위해 GFI, TLI, CFI, RMSEA 지수를 분석하였다. Table 5에 제시된 바와 같이, GFI = .93, $\mathrm{TLI}=.97, \mathrm{CFI}=.98, \mathrm{RMSEA}=.04$ 로 본 연구의 연구모형 적합 도는 적절한 구조모형의 기준을 충족시켰다. 
Table 5

Model Fit Indices for the Research Model

\begin{tabular}{cccccccc}
\hline & $\chi^{2}$ & $d f$ & $P$ & GFI & TLI & CFI & RMSEA \\
\hline Modified model & 107.75 & 84 & .041 & .93 & .97 & .98 & .04 \\
\hline
\end{tabular}

Table 6

Path Coefficient for the Final Model

\begin{tabular}{lllrrrr}
\hline & \multicolumn{2}{c}{ Pathway } & $B$ & $\beta$ & \multicolumn{1}{c}{ SE } & C.R \\
\hline Household chaos & $\rightarrow$ & Maternal negative parenting & .48 & $.52^{* * *}$ & .95 & 5.06 \\
Household chaos & $\rightarrow$ & Executive function & -1.23 & $-.25^{*}$ & .49 & -2.53 \\
Maternal negative parenting & $\rightarrow$ & Executive function & -1.44 & $-.27^{*}$ & .57 & -2.55 \\
Maternal negative parenting & $\rightarrow$ & Aggression & .31 & $.37^{* * *}$ & .83 & 3.78 \\
Executive function & $\rightarrow$ & Aggression & -.03 & $-.21^{*}$ & .15 & -2.31 \\
Child age & $\rightarrow$ & Executive function & 1.17 & $.62^{* * *}$ & .19 & 6.30
\end{tabular}

${ }^{*} p<.05 .{ }^{* * *} p<.001$.

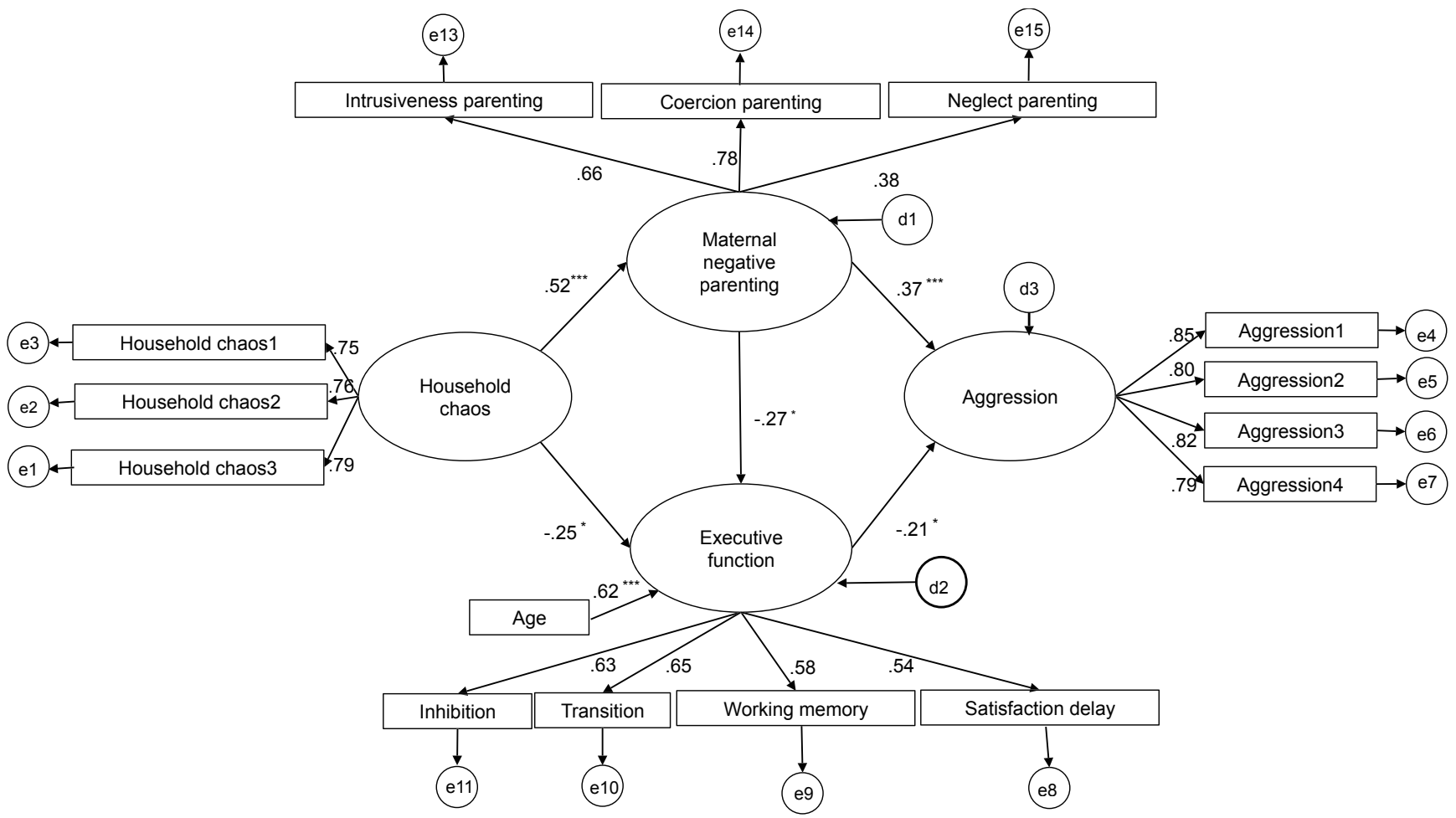

Figure 2. The Final Model: The Mediating Influence of Maternal Negative Parenting Behavior and Child Executive Function on the Relationships between Household Chaos and Child Aggression. ${ }^{*} p<.05 .{ }^{* * *} p<.001$.

최종모형의 경로계수를 알아보고, 통계적 유의성을 검증하 였다. 그 결과, 각 변인 간의 경로계수는 Table 6 과 같다. 가정 환경 혼돈 $\rightarrow$ 어머니의 부정적 양육행동 $(\beta=.52, p<.001)$, 가 정환경 혼돈 $\rightarrow$ 유아의 실행기능 $(\beta=-.25, p<.05)$, 어머니의 부정적 양육행동 $\rightarrow$ 유아의 실행기능 $(\beta=-.27, p<.05)$, 어머니 의 부정적 양육행동 $\rightarrow$ 유아의 공격성 $(\beta=.37, p<.001)$, 유아
의 실행기능 $\rightarrow$ 공격성 $(\beta=-.21, p<.05)$ 에 이르는 경로가 모두 유의하게 나타났다. 최종모형은 Figure 2와 같다.

구조모형 검증의 직·간접 효과 및 총효과 검증

주요 변인들 간의 직·간접효과·총효과의 통계적 유의성을 검 
Table 7

Direct, Indirect and Total Effects

\begin{tabular}{|c|c|c|c|c|c|}
\hline \multicolumn{3}{|l|}{ 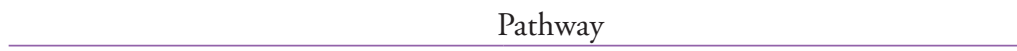 } & Direct effect & Indirect effect & Total effect \\
\hline Household chaos & $\rightarrow$ & Maternal negative parenting & $.52^{* * *}$ & - & $.52^{* * *}$ \\
\hline Household chaos & $\rightarrow$ & Executive function & $-.25^{*}$ & $-.14^{* *}$ & $-.39^{* *}$ \\
\hline Household chaos & $\rightarrow$ & Aggression & - & $.28^{* *}$ & $.28^{* *}$ \\
\hline Maternal negative parenting & $\rightarrow$ & Executive function & $-.27^{*}$ & - & $-.27^{*}$ \\
\hline Maternal negative parenting & $\rightarrow$ & Aggression & $.37^{* * *}$ & $.06^{* *}$ & $.43^{* *}$ \\
\hline Executive function & $\rightarrow$ & Aggression & $-.21^{*}$ & - & $-.21^{*}$ \\
\hline
\end{tabular}

${ }^{*} p<.05 .{ }^{* *} p<.01 .{ }^{* * *} p<.001$.

Table 8

Results of Bootstrapping with a Mediated Effect on Aggression

\begin{tabular}{lrrrr}
\hline \multicolumn{1}{c}{ Pathway } & Effect & SE & LLCI & ULCI \\
\hline Household chaos $\rightarrow$ Maternal negative parenting $\rightarrow$ Aggression & .15 & .05 & .066 & .267 \\
Household chaos $\rightarrow$ Executive function $\rightarrow$ Aggression & .04 & .03 & .001 & .143 \\
Household chaos $\rightarrow$ Maternal negative parenting $\rightarrow$ Executive function $\rightarrow$ Aggression & .02 & .02 & .005 & .082 \\
\hline
\end{tabular}

LLCI = Lower limit confidence interval; ULCL = Upper limit confidence interval.

${ }^{*} p<.05$.

증하기 위해서 부트스트랩방법(Bootstrap method)을 사용한 결과는 Table 7과 같다. 가정환경 혼돈이 유아의 공격성에 미 치는 직접효과는 나타나지 않았고, 어머니의 부정적 양육행동 혹은 유아의 실행기능을 매개로 하여 영향을 미치거나 어머니 의 부정적 양육행동과 유아의 실행기능을 이중매개로 하여 간 접적인 영향을 미쳤다 $(\beta=.28, p<.01)$.

다음으로 매개효과의 통계적 유의성을 검증하기 위해 부트 스트랩방법(Bootstrap method)을 사용한 결과는 Table 8과 같 다. 그 결과 어머니의 부정적 양육행동의 매개효과는 $95 \%$ 의 신뢰구간에서 .066 .267의 상한값과 하한값을 보였고, 유아 의 실행기능의 매개효과는 95\% 신뢰구간에서 .001 .143의 상한값과 하한값을 보였으며, 어머니의 부정적 양육행동과 유 아의 실행기능의 이중매개효과는 .005 .082의 상한값과 하 한값을 보이므로 세 경우 모두 0 을 포함하지 않는 것으로 나타 났다. 즉 가정환경 혼돈과 유아의 공격성 간의 관계에서 어머 니의 부정적 양육행동과 유아의 실행기능의 매개효과는 $p<$ .05 수준에서 통계적으로 유의한 것으로 확인되었다.

\section{Discussion}

본 연구의 목적은 가정환경 혼돈, 어머니의 부정적 양육행동,
유아의 실행기능 그리고 공격성의 관계를 알아보고 가정환경 혼돈과 유아의 공격성 간의 관계에서 어머니의 부정적 양육행 동과 유아 실행기능의 매개효과를 검증하였다. 이를 통해 유 아 공격성에 영향을 미치는 주요 변인들에 대해 이해를 넓히 고, 공격성의 감소 및 예방을 위한 방안에 도움을 줄 수 있는 기초자료를 제공하고자 하였다. 본 연구의 주요 결과를 요약 하고 논의하면 다음과 같다.

첫째, 가정환경 혼돈, 어머니의 부정적 양육행동, 유아의 실 행기능과 공격성 간의 상관관계를 분석한 결과, 유아의 공격 성은 가정환경 혼돈과 어머니의 부정적 양육행동과 정적 상관 관계가 나타났으며, 유아의 실행기능과는 부적 상관관계가 나 타났다. 이는 가정환경혼돈 수준이 높고 어머니가 부정적인 양육행동을 보일수록 유아의 공격성이 높아짐을 의미하며, 실 행기능이 낮을수록 높은 수준의 공격성을 보이는 것으로 나타 났다. 이를 통해 변수 간 상호관련성이 있음을 확인하여 관련 성을 종합적으로 살펴볼 필요가 있다.

둘째, 가정환경 혼돈과 유아의 공격성 간의 관계에서 어머 니의 부정적 양육행동의 매개효과가 나타났다. 즉 가정환경 혼돈이 유아의 공격성에 직접적으로 영향을 미치는 것이 아니 라 어머니의 부정적 양육행동을 통해 유아의 공격성을 유발 하는 것으로 볼 수 있다. 이는 어머니의 부정적 양육행동이 가 정환경 혼돈과 유아의 공격성 간의 관계를 매개한다는 연구 
(Mills-Koonce, 2016)와 맥을 같이 한다. 필요 이상의 과잉 자 극, 높은 수준의 소음, 구조화되지 않은 상태, 빠른 생활 속도 및 루틴의 결핍을 특징으로 하는 가정환경 혼돈 수준이 높을 수록 어머니는 자녀의 욕구에 민감하게 반응하지 못할 뿐 아 니라, 어머니의 피로감이나 심리적 고통이 누적되어 자녀에 게 부정적으로 반응하는 것으로 해석할 수 있다. 또한 혼돈스 러운 가정환경에 노출된 어머니는 정서를 적절하게 표현하 는 것이 어려워 자녀와의 민감한 상호작용에 참여하지 못해 부정적인 양육행동을 나타내었다(Andrews, 2020). 이러한 과 정이 반복되는 동안 자녀의 행동을 관찰할 기회가 적어져 어 머니의 양육효능감이 낮아지고, 이는 곧 개입적이고 강압적이 며, 방임적인 양육행동을 증가시키게 된다(Dumas et al., 2005). 그 결과 유아는 자신의 욕구가 충족되지 않는 상황에서 더 많 은 공격성을 보인다(Park \& Kang, 2012). 구체적으로 높은 수 준의 가정환경 혼돈으로 인해 어머니는 자녀를 지나치게 통 제하거나 개입하는 양육행동을 하고, 이는 유아로 하여금 분 노를 유발시키게 된다(Kim, $\mathrm{Kim}, \& \mathrm{Kim}, 2010)$. 이러한 경험 이 축적되면 유아는 타인에 대해 불신을 가지게 되어 공격적 인 행동을 보일 수 있다. 그리고 어머니가 자녀를 신체적으로 때리거나 고함을 지르는 강압적 양육행동을 자주 보이는 경우 유아가 이를 모방하여 공격성을 많이 보이기도 한다(Chung \& $\mathrm{Kim}, 2011$; Jun \& Kim, 2009). 또한 어머니가 자녀에게 무관심 한 방임적인 양육행동을 보일 경우 적절한 훈육이 부족하게 되어 규칙이나 기대를 명확하게 배우는 기회가 적어 공격적 인 행동으로 이어질 수 있다(Y. S. Kong, 2012). 이와 같이 가정 환경 혼돈은 어머니의 부정적 양육행동을 매개로 하여 유아의 공격성에 영향을 미치는 것을 확인할 수 있다. 따라서 유아의 공격성을 예방하기 위해서는 규칙적인 일과가 있는 구조화된 가정환경을 조성함으로써 어머니의 부정적인 양육행동을 감 소시킬 필요가 있다.

셋째, 가정환경 혼돈과 유아의 공격성 간의 관계에서 실행 기능의 매개효과가 나타났다. 가정환경이 혼돈할수록 유아의 실행기능 발달이 저해되고, 이는 유아의 공격성을 높이는 것 을 의미한다. 즉 가정환경이 구조화되지 않고 과잉 자극이 존 재할수록 유아는 자신의 정서와 행동을 조절하기 어려워 타인 을 신체적으로 때리고 미는 공격적인 행동을 유발하는 것으로 생각된다. 이러한 연구 결과는 실행기능의 한 측면인 억제가 가정환경 혼돈과 유아의 공격성 간의 관계를 매개한다는 연구 (Hardaway, Wilson, Shaw, \& Dishion, 2012)와 유사한 결과이다. 또한 가정환경이 혼돈할수록 높은 스트레스로 인해 실행기능 과 관련 있는 전전두엽의 조절 기능에 영향을 미쳐 유아의 실
행기능이 저하되고(Andrews, 2020) 이는 유아가 충동성을 조 절하기 어려워 타인에게 높은 수준의 공격성을 보였다는 연구 (O’Toole, Monks, \& Tsermentseli, 2017)를 지지하는 결과이다.

이러한 결과는 유아의 공격성에 영향을 미치는 중요한 개 인 요인인 실행기능의 중요성을 확인한 것이라 할 수 있다. 낮 은 수준의 실행기능은 상황에 대한 이해와 타인의 정서를 정 확하게 인식하기 어려워 공격적인 행동을 보이는 것으로 해 석할 수 있다. 더불어 실행기능이 낮은 유아는 분노와 같은 부 정적인 감정을 많이 느끼고 자신의 행동을 수정하는 능력이 부족하여 갈등상황에서 공격성을 빈번하게 나타내는 것으 로 보인다. 또한 실행기능은 가정환경 혼돈의 영향을 받는데, Martin 등의 연구 (2012)에 따르면 반복되는 일과가 있는 가정 환경에서 유아는 앞으로의 상황을 예측할 수 있고, 이는 기다 림에 대한 보상이 있음을 인식할 수 있다고 하였다. 반면 예측 이 불가능한 가정환경에서는 보상의 기회가 불규칙하여 기다 림에 대한 보상을 인식하기 어려워 즉각적인 보상을 선택할 가능성이 높다고 하였다. 또한 혼돈스러운 가정환경에서 유 아는 자신이 안전하다고 인식하기 어려워 상황에 따라 각성 을 조절하기보다 항상 높은 수준의 각성상태를 유지하여 실 행기능이 저해된 것으로 나타났다(Martin, Razza, \& B-Gunn, 2012). 이를 통해 가정환경 혼돈은 유아의 실행기능을 매개로 하여 공격성에 영향을 미치는 것을 확인 할 수 있다. 따라서 유 아의 공격성을 낮추기 위해서는 유아가 실행기능을 발달시킬 수 있도록 가정에서 일관되고 과도한 자극이 없는 환경을 제 공할 필요가 있다.

넷째, 가정환경 혼돈과 유아의 공격성의 관계에서 어머니 의 부정적 양육행동과 유아의 실행기능의 중다매개효과가 나 타났다. 이는 가정환경 혼돈이 유아의 공격성에 직접적인 영향 을 미치는 것이 아니라 어머니의 부정적 양육행동과 유아의 실 행기능을 통해 공격성에 간접적인 영향을 미치는 것으로 해석 된다. 즉, 가정환경 혼돈 수준이 높을수록 어머니가 자녀에게 개입적이고 강압적이며 방임적인 양육행동을 하게 되고, 이러 한 부정적인 양육행동으로 인해 유아 자신의 사고와 행동을 조 절하는 능력인 실행기능이 저하되어 높은 수준의 공격성을 보 인다. 본 연구 결과는 생의 초기 가정환경 혼돈 수준이 유치원 시기의 행동 조절력에 미치는 종단적 영향을 검증한 VernonFeagans 등 (2016)의 연구를 지지한다. 구체적으로, 생후 3년 동 안 가정환경 혼돈 수준이 높았던 가정의 어머니는 자녀에 대한 반응성과 수용성 수준이 낮았으며, 이는 36 개월경에 측정된 자 녀의 실행기능을 낮춤으로써 궁극적으로는 유치원 시기 동안 과잉행동 및 주의력 결핍 가능성을 증가시켰다. 또한 Garrett- 
Peters, Mokrova, Carr, 그리고 Vernon-Feagans (2019)의 종단연구 에 의하면, 출생 후 5년 동안 가정환경 혼돈수준이 높을수록 6 60개월 동안 부모가 자녀에게 덜 반응적이었으며, 이는 유치 원 시기의 자기조절력 수준을 낮춤으로써 초등학교 3학년 시 기의 학교 참여도에도 부정적인 영향을 미쳤다. 이들 연구들은 가정환경 혼돈이 유아의 부적응 행동 혹은 적응 행동에 직접적 인 영향을 미치기보다는 부모의 양육행동과 아동 개인적 요인 을 매개로 하여 간접적인 영향을 미침을 보여준다. 따라서 높 은 청각적 소음과 구조화되지 않는 가정환경은 어머니로 하여 금 피로감을 제공하여 유아의 발달이 촉진될 수 있는 환경을 제공하지 않아 유아의 실행기능 수준이 낮아졌음을 예상할 수 있다. 이러한 낮은 수준의 실행기능은 자신의 행동을 억제하기 어렵고 행동에 대한 결과를 예측하지 못하여 타인을 공격하는 행동을 유발한 것으로 생각된다.

본 연구에서는 가정환경 혼돈이 유아의 공격성에 영향을 미치는 심리적 과정을 확인할 수 있었다. 특히 유아의 공격성 에 직접적인 영향을 미치는 실행기능은 환경과의 상호작용을 통해 발달할 수 있다(Glaser, 2000). 이와 관련하여 본 연구의 결과는 가정환경이 혼돈할수록 어머니의 부정적 양육행동에 영향을 미쳐 유아의 실행기능을 저하시키는 것을 밝혔다. 이 는 어머니가 지속적으로 가정환경 혼돈에 노출될수록 환경을 통제할 수 없다는 무력감과 우울감을 느껴 자녀에게 부정적인 양육행동을 보이고, 이러한 양육행동은 전두엽 활성화를 방해 하여(K. Cha, 2015) 실행기능을 저하시키는 것으로 해석할 수 있다. 따라서 본 연구 결과는 가정환경 혼돈이 유아의 공격성 에 미치는 경로에서 어머니의 부정적 양육행동과 유아의 실행 기능의 연속적인 과정을 살펴봄으로써 유아의 공격성을 예방 하기 위해서는 유아의 실행기능 발달에 영향을 미치는 어머니 의 부정적 양육행동과 가정환경 혼돈 수준을 낮추는 것이 중 요함을 시사한다.

본 연구의 제한점과 제언은 다음과 같다.

첫째, 본 연구에서는 가정환경 혼돈과 어머니의 부정적 양 육행동과의 양방향성을 고려하지 않았다. Garrett-Peters (2019) 등에 따르면 어머니가 부정적인 양육행동을 보일수록 가정에 서 안정된 환경을 구성하기 어려워 무질서하고 예측이 불가능 한 가정환경 혼돈을 유발할 가능성이 있음을 제기하였다. 따 라서 후속 연구에서 가정환경 혼돈과 어머니의 부정적 양육행 동의 양방향성을 고려할 필요가 있다.

둘째, 본 연구에서는 공격성과 실행기능, 어머니의 부정적 양육행동의 하위유형을 고려하지 않았다. 우선 공격성은 신체 적 공격성과 관계적 공격성, 적대적 공격성과 도구적 공격성
(Crick \& Grotpeter, 1995; Shaffer, 1996)등으로 구분할 수 있으 므로, 후속 연구에서는 공격성을 유형별로 나누어 살펴 볼 필 요가 있다. 유아의 공격성에 인지적 실행기능 보다 정서적 실 행기능의 영향력이 크다는 연구(Y. S. Kong, 2012)를 고려해 볼 때, 실행기능의 하위유형별로 유아의 공격성에 미치는 영향을 살펴 볼 필요가 있다. 본 연구에서는 어머니의 부정적 양육행 동을 하나의 변인으로 다루었으나 개입적, 강압적, 방임적 양 육행동이 유아의 발달에 미치는 영향이 각각 다를 수 있으므 로 후속 연구에서는 하위 차원에 따른 접근이 필요하다.

셋째, 가정환경 혼돈 척도의 일부 문항의 내용이 모호하여 (“우리 집은 돼지우리 같다.”, “우리 집에는 자주 야단법석이 일어난다.”) 추후 척도의 국내 타당화가 필요하다. 또한 본 연 구에서 사용한 가정환경 혼돈 척도는 하위요인이 없는 단일요 인이지만, 가정환경 혼돈을 관찰을 통해 측정한 국외 연구에 서는 무질서(disorder)와 불안정성(instability)을 구분하여 측정 하였다. 선행연구(Vernon-Feagans et al., 2012)에 따르면 가정환 경 혼돈의 무질서 측면만이 유아의 발달에 영향을 미침을 알 수 있다. 따라서 후속 연구에서는 가정환경 혼돈을 관찰을 통 해 측정하여 각 하위 차원에 따른 결과를 제시할 필요가 있다.

넷째, 본 연구에서는 유아의 공격성을 예측하는 개인적 요 인으로 실행기능을 살펴보았다. 다수의 선행연구에 따르면, 유아의 공격성은 좌절, 분노와 같은 부정적 정서를 인식하고 이를 조절할 수 있는 능력과 타인의 정서를 이해할 수 있는 정서적 특성과의 높은 관련성이 있음을 보고하고 있다(Kim, Wang, \& Kim, 2017; B. L. Suh, 2018). 따라서 후속 연구에서는 유아의 공격성에 영향을 미치는 개인적 요인으로 정서적 특성 을 고려할 필요가 있다.

이러한 제한점에도 불구하고 본 연구는 실행기능을 유아가 직접 수행하는 행동을 관찰하여 측정하였다는 점에서 의미가 있다. 통제된 상황에서의 과제 측정 방식은 실행기능 각 요소 의 특정 정보를 얻을 수 있으며, 타인에 의해 평가되었기 때문 에 객관적일 수 있다(G. A. Lee, 2021). 따라서 본 연구에서는 유아의 실행기능을 제 3 자가 직접 측정하여 연구 결과의 타당 성 확립에 도움이 될 것으로 생각된다.

더불어 가정환경 혼돈이 어머니의 부정적인 양육행동과 유 아의 실행기능을 순차적으로 매개하여 유아의 공격성에 간접 적인 영향을 미친다는 결과를 고려해볼 때 유아의 공격성을 예방하기 위해서는 자신의 사고와 행동을 조절하는 실행기능 을 발달시키는 것이 중요하다는 시사점을 얻을 수 있다. 더불 어 유아의 실행기능 발달을 위해서는 어머니의 부정적 양육행 동을 감소시키고 구조화되고 안정적인 가정환경이 중요하다 
는 결론을 도출할 수 있다. 이러한 결과는 공격적인 유아를 위 한 유아교육기관 및 상담 현장에서 부모교육의 기초자료에 도 움을 줄 수 있을 것이다.

\section{Notes}

This article is a part of the first author's master's thesis submitted in 2021, and was presented as a poster at the 2021 Annual Spring Conference of the Korean Association of Child Studies.

\section{Conflict of Interest}

No potential conflict of interest relevant to this article was reported.

\section{References}

\section{In English}

Andrews, K. (2020). Household chaos, maternal distress and parenting: Associations with child function across multiple domains (Doctoral dissertation). Retrieved from http://hdl. handle.net/11375/25351

Bernier, A., Carlson, S. M., \& Whipple, N. (2010). From external regulation to self-regulation: Early parenting precursors of young children's executive functioning. Child Development, 81(1), 326-339. doi:10.1111/j.1467-8624.2009.01397.x

Broidy, L. M., Nagin, D. S., Tremblay, R. E., Bates, J. E., Brame, B., Dodge, K. A., et al. (2003). Developmental trajectories of childhood disruptive behaviors and adolescent delinquency: A six-site, cross-national study. Developmental Psychology, 39(2), 222-245. doi:10.1037/0012-1649.39.2.222

Coldwell, J., Pike, A., \& Dunn, J. (2006). Household chaoslinks with parenting and child behaviour. Journal of Child Psychology and Psychiatry, 47(11), 1116-1122. doi:10.1111/ j.1469-7610.2006.01655.x

Crick, N. R., \& Grotpeter, J. K. (1995). Relational aggression, gender, and social-psychological adjustment. Child Development, 66(3), 710-722. doi:10.2307/1131945

Dumas, J. E., Nissley, J., Nordstrom, A., Smith, E. P., Prinz, R. J., \& Levine, D. W. (2005). Home chaos: Sociodemographic, parenting, interactional, and child correlates. Journal of Clinical Child and Adolescent Psychology, 34(1), 93-104. doi:10.1207/s15374424jccp3401_9

Ellis, M. L., Weiss, B., \& Lochman, J. E. (2009). Executive functions in children: Associations with aggressive behavior and appraisal processing. Retrieved from ERIC database. (EJ852952)

Evans, G. W., \& Stecker, R. (2004). Motivational consequences of environmental stress. Journal of Environmental Psychology, 24(2), 143-165. doi:10.1016/S0272-4944(03)00076-8

Evans, G. W., \& Wachs, T. D. (2010). Chaos and its influence on children's development. Washington, DC: American Psychological Association.

Frye, D., Zelazo, P. D., \& Palfai, T. (1995). Theory of mind and rule-based reasoning. Cognitive Development, 10(4), 483527. doi:10.1016/0885-2014 (95)90024-1

Garon, N., Bryson, S. E., \& Smith, I. M. (2008). Executive function in preschoolers: A review using an integrative framework. Psychological Bulletin, 134(1), 31-60. doi:10.1037/0033-2909.134.1.31

Garrett-Peters, P. T., Mokrova, I. L., Carr, R. C., \& VernonFeagans, L., \& The Family Life Project Key Investigators. (2019). Early student (dis) engagement: Contributions of household chaos, parenting, and self-regulatory skills. Developmental Psychology, 55(7), 1480-1492. doi:10.1037/ $\operatorname{dev} 0000720$

Gerstadt, C. L., Hong, Y. J., \& Diamond, A. (1994). The relationship between cognition and action: Performance of children 3-7 years old on a stroop-like day-night test. Cognition, 53(2), 129-153. doi:10.1016/0010-0277(94) 90068-x

Glaser, D. (2000). Child abuse and neglect and the brain-a review. Journal of Child Psychology and Psychiatry, 41(1), $97-$ 116. doi:10.1111/1469-7610.00551

Graziano, P. A. (2009). Developmental trajectories of "hot" executive functions across early childhood: Contributions of maternal behavior and temperament. (Doctoral dissertation). Retrieved from https://libres.uncg.edu/ir/uncg/listing.aspx?id=2315

Hardaway, C. R., Wilson, M. N., Shaw, D. S., \& Dishion, T. J. (2012). Family functioning and externalizing behaviour among low-income children: Self-regulation as a mediator. Infant and Child Development, 21(1), 67-84. doi:10.1002/ icd.765

Kline, R. B. (2015). Principles and practice of structural equation modeling (4th ed.). New York: Guilford Press.

Marion, M. (1994). Encouraging the development of responsible anger management in young children. Early Child Development and Care, 97(1), 155-163. doi:10.1080/03004 43940970112

Martin, A., Razza, R. A., \& B-Gunn, J. (2012). Specifying the links between household chaos and preschool children's development. Early Child Development and Care, 182(10), 
1247-1263. doi:10.1080/ 03004430.2011.605522

Millgram, S. (1970). The experience of living in cities. Science, 167(3924), 1461-1468. doi:/10.1037/10042-011

Mills-Koonce W. R., Willoughby M. T., Garrett-Peters P., Wagner N., Vernon-Feagans L. (2016) The interplay among socioeconomic status, household chaos, and parenting in the prediction of child conduct problems and callousunemotional behaviors. Development and Psychopathology, 28(3), 757-771. doi:10.1017/S0954579416000298

O’Toole, S. E., Monks, C. P., \& Tsermentseli, S. (2017). Executive function and theory of mind as predictors of aggressive and prosocial behavior and peer acceptance in early childhood. Social Development, 26(4), 907-920. doi:10.1111/ sode. 12231

Prencipe, A., \& Zelazo, P. D. (2005). Development of affective decision making for self and other: Evidence for the integration of first-and third-person perspectives. Psychological Science, 16(7), 501-505. doi:10.1111/j.09567976.2005.01564.x

Pruitt, D. B. (Ed.). (1998). Your child: What every parent needs to know: what's normal, what's not, and when to seek help. New York: Harper Collins. doi.:10.1176/appi.ajp.158.6.977

Shaffer, D. R. (1996). Developmental psychology: Childhood and adolescence(4th ed.). California: Brooks Cole.

Sytsma, S. E., Kelley, M. L., \& Wymer, J. H. (2001). Development and initial validation of the child routines inventory. Journal of Psychopathology and Behavioral Assessment, 23(4), 241-251. doi:/10.1023/ A:1012727419873

Vernon-Feagans, L., Garrett-Peters, P., Willoughby, M., \& MillsKoonce, R., \& The Family Life Project Key Investigators. (2012). Chaos, poverty, and parenting: Predictors of early language development. Early Child Research Quarterly, 27(3), 339-351. doi:10.1016/j.ecresq.2011.11.001

Vernon-Feagans, L., Willoughby, M., \& Garrett-Peters, P., \& The Family Life Project Key Investigators. (2016). Predictors of behavioral regulation in kindergarten: Household chaos, parenting, and early executive functions. Developmental Psychology, 52(3), 430-441. doi:10.1037/dev0000087

Volckaert, A., \& Noel, P. M. -P. (2018). Executive function, chaos and temperament: Specificities in preschoolers with externalizing behaviors. Psychologica Belgica, 58(1), 222242. doi: $10.5334 / \mathrm{pb} .352$

Wachs, T. D., \& Evans, G. W. (2010). Chaos in context. In G. W. Evans \& T. D. Wachs (Eds.), Chaos and its influence on children's development: An ecological perspective (pp. 3-13). American Psychological Association. doi:10.1037/12057001

Welsh, M. C., Pennington, B. F., \& Groisser, D. B. (1991). A normative developmental study of executive function: A window on prefrontal function in children. Developmental
Neuropsychology, 7(2), 131-149 doi:10.1080/875656 49109540483

Zelazo, P. D., \& Muller, U. (2002). Executive function in typical and atypical de-velopment. In U. Goswami (Ed.) Blackwell handbook of childhood cognit-ive development (pp. 445-469). Malden, MA: Blackwell

\section{In Korean}

Cha, K. (2015). Maternal interaction behaviors and the development of executive functions among Korean preschoolers. Korean Journal of Early Childhood Education, 35(2), 117-141. doi:10.18023/kjece.2015.35.2.006

Choi, C. Y. (2019) Family processes in infancy and early childhood of children's aggression and social withdrawal at school entry (Master's thesis). Retrieved from https://www.riss.kr/ link?id=T15120117

Chung, J. -N., \& Kim, J. (2011). The effects of maternal rejective parenting behaviors and preschoolers' aggression and social skills on preschoolers' exclusion by peers. Korean Journal of Human Ecology, 20(5), 983-992.

Choi, S. -N., \& Moon, Y. -K. (2016). The influences of child daily stress and parental discipline style, preschooler's problem behaviors according to the gender. Korea Journal of Child Care and Education, 97, 125-156.

Jeong, M. S., \& Lee, H. Y. (2014). The mediating effects of parental rejective parenting and teacher-child conflictual relation on young children's aggression and adjustment to early childhood education institution. The Journal of Child Education, 23(4), 377-390.

Jo, H. Y., \& Chung, H. C. (2020). The effects of aggression reduction programs for young children: A systematic review and meta-analysis. The Korean Society for Childhood Education, 40(1), 63-81. doi:10.18023/kjece.2020.40.1. 003

Kang, D. Y., \& Park, J. H. (2020). The effects of household chaos on preschoolers' self-control: The moderating effects of teachers' limit-setting style. Korean Journal of Childcare and Education, 16(1), 75-98. doi:10.14698/ jkcce.2020.16.01.075

Kim, A.-L., Wang, Y. Y., \& Kim, M. (2017). Impact of mother's emotional socialization on child's aggression: The mediating effect of child's emotional regulation. The Korean Journal of Human Development, 24(3), 197-217. doi:10.15284/ kjhd.2017.2 4.3.197

Kim, H. J., \& Kim, Y. H. (2011). Effects of mother's parenting, children's temperament, emotional regulation, and aggression on peer competence. J. of Human Ecology, 15(2), 31-45.

Kim, J. (2013). Preschoolers emotion regulation in different 
situations: Related to executive function and temperament (Doctoral dissertation). Retrieved from http://www.riss.kr/ link?id=T13143372

Kim, M. J., \& Doh, H. S. (2001). The influence of parenting behaviors, marital conflict and sibling relations on aggression in children. Korean Journal of Child Studies, 22(2), 149-166.

Kim, S., \& Shin, N. (2020). The effects of maernal parenting behavior on preschoolers' social behavior: The mediatitng effect of preschoolers' executive function. Korean Journal of Clinical Psychology, 16(5), 47-67. doi:.10.14698/ jkcce.2020.16.05.047

Kim, Y. A., Lee, J., Moon, S. -J., Kim, Y. -J., \& Oh, K. J. (2009). Standardization study for the korean version of the child behavior checklist for ages 1.5-5. Korean Journal of Clinical Psychology, 28(1), 117-136.

Kim, I. S., Kim. Y. J., \& Kim, Y. H. (2010). The effects of attachment to the mother, mother's parenting style $\&$ young children's emotional regulation on aggression. Journal of Educational Studies, 41(3), 175-202.

Kong, Y. S. (2012). The effect of preschooler's temperament and maternal parenting attitude on preschooler's problem and prosocial behavior-Focusing on the mediating effect of executive function (Doctoral dissertation). Retrieved from http:// www.riss.kr/link?id=T12699288

Lee, G. A. (2021). Developing the prediction model for children's executive function using machine learning (Doctoral dissertation). Retrieved from http://www.riss.kr/ link?id=T15765496

Hong, H. J., \& Moon, H. J. (2013). The effect of children's temperament, mother's parenting behavior, and teacherchild relationships on children's behavior problems. The Journal of Eco Early Childhood Education \& Care, 12(4), 245-274.

$\mathrm{Na}$, J. (2012). Maternal and paternal parenting behaviors affecting preschooler's social competence (Master's thesis). Retrieved from http://www.riss.kr/link?id=T12845592

Oh, Y. \& Yeon, G. S. (2018). An analysis of the relationships among parenting stress of mothers, self-esteem of children, externalizing problem behavior and intellectual capacity of children. Journal of Parent Education, 10(1), 31-50.

Park, H. W., \& Lee, Y. (2013). Development of executive function in 3-7 year Olds: Analyses by age and maternal employment. The Korean Journal of Developmental Psychology, 26(1), 137-155.

Park, M-J., \& Kang, J. H. (2012). Effects of infant temperament, their parents' conflict and parenting behaviors on externalizing problem behaviors of infants. Journal of Emotional \& Behavioral Disorders, 28(4), 331-352.

Shin, S. B. (2019). A study on the young children's cognitive ability, executive function and self-regulation ability according to age (Master's thesis). Retrieved from http://www.riss.kr/ link?id=T15075036

Suh, B. L. (2018). Gender difference in mediating effect of emotion regulation on the relationship between maternal response to children's negative emotions and children's aggression (Master's thesis). Retrieved from http://www.riss.kr/ link?id=T14858989

Youn, J. -J., Kang, S. -Y., \& Lee, B. -J. (2005). A study for young children's aggression and relationship of relative factorsconcentrating on young children's temperament, selfregulation and mother's parenting efficacy, parenting behaviors. Korean Journal of Human Ecology, 14(5), 761-770.

\section{ORCID}

Jeong Min Lee http://orcid.org/0000-0002-8880-3187

Sunhee Kim http://orcid.org/0000-0002-0801-6918

Received October 31, 2021

Revision received November 23, 2021

Accepted December 4, 2021 